\title{
WW Domain-Containing Oxidoreductase is a Potential Receptor for Sex Steroid Hormones
}

\author{
Won-Pei Su${ }^{1}$, Shu-Hui Chen ${ }^{2}$, Szu-Jung Chen ${ }^{1}$, \\ Pei-Yi Chou ${ }^{1}$, Chun-Cheng Huang1 and Nan-Shan Chang ${ }^{1,3,4}$ \\ ${ }^{1}$ Institute of Molecular Medicine, \\ National Cheng Kung University, Tainan, Taiwan, \\ ${ }^{2}$ Department of Chemistry, \\ National Cheng Kung University, Tainan, Taiwan, \\ ${ }^{3}$ Department of Neuroscience and Physiology, SUNY \\ Upstate Medical University, Syracuse, NY, \\ ${ }^{4}$ Department of Neurochemistry, NYS Institute of Basic \\ Research in Developmental Disabilities, Staten Island, NY, \\ $1,2 R O C$ \\ 3,4 USA
}

\section{Introduction}

\subsection{Biosynthesis and metabolism of estrogens}

Estrogen is a steroid hormone that comprises a group of compounds, including estrone (E1), estradiol (E2) and estriol (E3). E2 is an ovarian hormone necessary for the development of secondary sexual characteristics and function of the reproductive system in females. It also plays important roles in non-reproductive organs by multiple pathways. Estrogens are produced primarily by developing follicles in the ovaries, the corpus luteum, and the placenta. Some estrogens are also produced in smaller amounts by other tissues such as the liver, adrenal glands, and the breasts. E2 is converted from testosterone and E1 from rostenedione; both conversions are regulated by a dehydrogenase enzyme, aromatase. Estrogens are eliminated from the body by metabolic conversion to hormonally inactive and water-soluble metabolites that are excreted in the urine and/or feces. The metabolic disposition of estrogens includes oxidative metabolism (Martucci et al., 1993) and conjugative metabolism by glucuronidation (Zhu, et al., 1996), sulfonation (Hernandez et al., 1992) and/or O-methylation (Ball \& Knuppen, 1980). Hydroxylation at the C-2 and C-4 position of E2 (17 $\beta$-Estradiol) yields the catecholestrogens (CEs), 2-hydroxyestrone (2OHE1) and 2-hydroxyestradiol (2-OHE2), 4-hydroxyestrone (4-OHE1) and 4hydroxyestradiol (4-OHE2) while hydroxylation at the C-16 $\alpha$ position yields $16 \alpha$ hydroxyestrone (16 $\alpha$-OHE1), which is subsequently converted to estriol (E3) (Ball \& Knuppen, 1980; Zhu \& Conney, 1998). The hydroxylated products exert very different biological properties: the $16 \alpha$-hydroxy and 4-hydroxy metabolites are active estrogens, 
whereas the 2-hydroxy metabolites are not as active (Fishman \& Martucci, 1980; Swaneck \& Fishman, 1988). However, the binding and redox cycling activities of CEs can be blocked via O-methylation by catechol-O-methyltransferase (COMT), which converts 2-OHE1/E2 and 4OHE1/E2 to their methoxy derivatives 2-MeOHE1, 2-MeOHE2, 4-MeOHE1, and 4MeOHE2, respectively (Albin et al., 1993; Cheng et al., 1998; Falany \& Falany, 1996). Although liver is the major organ of the estrogen metabolism, some estrogen hydroxylation enzymes are selectively expressed in other tissues. Our recent data indicated that trace amounts $(<0.9 \mathrm{fg} /$ cell) of estrogens are produced in the endogenous breast cancer cells (MCF-7) (Huang et al., 2011). Moreover, E2 treatment substantially induced E1 and estrogen metabolites in MCF-7 cells, indicating the expression of estrogen metabolizing enzymes in breast cancer cells as well.

\subsection{Estrogen receptors}

E2 is most known to act by binding to and activating two estrogen receptors (ERs), ER $\alpha$ and ER $\beta$ (Mosselman et al., 1996), which belongs to the super-family of nuclear receptors (McDonnel \& Norris, 2002). Like many nuclear receptors, ERs are consisted of hypervariable $\mathrm{N}$-termini that contribute to the transaction function; namely, a highly conserved DNA binding domain responsible for DNA binding and dimerization and C-terminal domain, which is involved in ligand binding, nuclear localization, and ligand-dependent transaction function. It is well established that E2 can activate ER $\alpha$ and promote cancer formation in experimental animals, which is associated with cell proliferation. In contrast, the activated ER $\beta$ suppresses cell proliferation and colon cancer xenograft growth, probably as a consequence of ER $\beta$-mediated inhibition of cell-cycle pathways (Hartman et al., 2009). E2 action involves ligand-mediated activation of ER $\alpha$ and $E R \beta$, which binds directly with estrogen response element (ERE) in the promoters of target genes and recruits various coactivators to mediate transcriptional regulation. There is a general consensus that hormonally active compounds may directly or indirectly activate transcription factors through ER binding and promote gene transcription and cell proliferation, in particular in cells responding to the hormones by growth. Many anti-cancer drugs for estrogendependent breast tumor have been developed based on their antagonistic effect on E2 binding so as to affect protein expression.

\subsection{Non-classical estrogen actions}

E2, however, could also induce estrogenic effects in ER-negative systems through signaling pathways more commonly associated with growth factor activation of cell surface receptors such as G-protein-coupled receptor (GPCR) GPR30 to transactivate epidermal growth factor receptor (EGFR) and activate the MAPK cascade via the release of surface-associated heparin binding epidermal growth factor (Filardo et al., 2002). E2 may also trigger the transcription of non-estrogen responsive genes through kinase activation. It has been demonstrated that this GPR30-dependent estrogen induction of MAPK is transient and under the control of a cAMP-dependent negative feedback loop. Whereas, our phosphoproteomics data (Wu et al., 2011) suggested that the growth factor-mediated pathways also occur in ER-dependent cells. Furthermore, accumulating evidence reveals that many unexpected non-classical responses such as estrogen-derived reactive oxidative stress (ROS) may also be induced (Yeh et al., 2005; Miro et al., 2011). The interaction between estrogen-derived ROS and proliferation machinery has not been elucidated yet. 


\subsection{Non-classical estrogen receptors}

Based on a review of data scattered in the literature, we suggest that some of the effects exerted by active estrogen may be mediated by specific intracellular receptors or effectors, which are different from the classical estrogen receptor. It is most likely that additional isoforms of the classical ERs or putative receptors with the ligand binding domain are potential candidates of E2 receptors. Moreover, active estrogen metabolites such as catechol estrogens are not merely to simplify the secretion of estrogen, but may have their own biological roles (Zhu \& Conney, 1998). Receptors of estrogen metabolites are distinct and different from classical ERs (Markides \& Liehr, 2005). A locally formed estrogen metabolite may exert a biological effect important for the action of the parent hormone. Cytochrome P450 family are the major enzymes catalyzing nicotinamide adenine dinucleotide phosphate (reduced form) $\left(\mathrm{NADPH}^{*}\right)$-dependent oxidative metabolism of estrogens to multiple hydroxylated metabolites. The estrogen biosynthesis enzyme, aromatase, whose function is to aromatize androgens in order to produce estrogens, is a member of the cytochrome P450 superfamily. Since estrogen and estrogen metabolites are substrates of specific reductases or oxidases, we suspect that cellular proteins, which possess an oxidoreductase domain, are candidates of novel estrogen receptors. These novel receptors may possess important and unique biological functions that are not directly associated with the classical estrogen action.

\section{Oxidoreductases and sex steroid hormones}

\section{$2.117 \beta$-hydroxysteroid dehydrogenases}

Biologically active sex steroid hormones are metabolically converted in normal and cancerous tissues and organs. Estrogen provides a proliferative effect in majority of ERpositive breast cancer cells. Enzymes responsible for metabolizing steroid hormones are aromatase, estrone sulfatases, and 17 $\beta$-hydroxysteroid dehydrogenases (17 $\beta$-HSDs) (Jansson, 2009; Aka et al., 2009). These enzymes are present in breast cancer tissues (Miki et al., 2009). There are reductive and oxidative $17 \beta$-HSDs. The reductive $17 \beta$-HSDs are responsible for manufacturing active androgens and estrogens by catalyzing the formation of the hydroxy group at position $17 \beta$ of the steroid backbone. The oxidative $17 \beta-H S D$ transforms the hydroxy group into keto and inactivates the steroids. The type $317 \beta-\mathrm{HSD}$ $(17 \beta-H S D 3)$ is reductive, structurally similar to $17 \beta-H S D 12$, and present in the testis. $17 \beta-$ HSD3 recognizes androgen by catalyzing the transformation of 4 -androstenedione into testosterone (Geissler et al., 1994). 17 $\beta$-HSD12 catalyzes the transformation of both androgens and estrogens (Blanchard \& Luu-The, 2007; Liu et al., 2007). Caenorhabditis elegans LET-767 is known to metabolize androgens and estrogens, and the gene appears to share a common ancestor with human types $17 \beta-H S D 3$ and HSD12 (Desnoyers et al., 2007). High levels of expression of $17 \beta-H S D 1$ have been shown to be associated with poor prognosis in breast cancer and late relapse among patients with ER-positive breast tumors (Sasaki et al., 2010; Jansson et al., 2009). In contrast, significant downregulation of 17 $\beta$-HSD2 is also correlated with decreased survival in ER-positive breast cancer (Sasaki et al., 2010; Jansson et al., 2009). Similarly, significantly reduced expression of 17 $\beta$-HSD14 mRNA in breast cancer is also associated with decreased survival (Jansson et al., 2009). Overall, there are 14 different types of $17 \beta-H S D$ s (Marchais-Oberwinkler et al., 2011). These oxidoreductases are central to the estrogen and androgen steroid metabolism by catalyzing final steps of the steroid biosynthesis. Indeed, $17 \beta-H S D s$ act like receptor molecules. While these proteins are involved in many diseases such as breast cancer, prostate cancer, endometriosis, osteoporosis, and brain cancer, $17 \beta$-HSDs are of considerable interest in therapeutic targeting. 


\subsection{Estrogen metabolites and biological effects}

Despite the wealthy knowledge of estrogen/ER in signaling, metabolism and diseases (Tam et al., 2011; Okoh et al., 2011; Nilsen, 2008; Mueck \& Seeger, 2007; Straub, 2007), the signal pathways underlying the biological effects of estrogen metabolites are largely unknown. Estrogen metabolites could provide growth signal for cancer cells, and yet they may become toxic to normal cells (Obi et al., 2011; Sepkovic \& Bradlow, 2009; Chen at al., 2008). The metabolites may invoke inflammatory lung diseases such as asthma, cystic fibrosis, and chronic obstructive pulmonary disease in women (Tam et al., 2011). Estrogen metabolite 16a-hydroxyestrone exerts estrogenic activity through covalent ER binding, whereas 2hydroxyestrone would have anti-estrogenic capabilities (Obi et al., 2011). The ratios of these metabolites appear to be critical in controlling breast cancer cell growth. 2-Hydroxyestradiol and 4-hydroxyestradiol are implicated in tumorigenesis via increasing cell proliferation and the formation of reactive oxygen species for possibly generating deoxyribonucleic acid mutations (Joubert et al., 2009). The E2 metabolite 2-methoxyestradiol exerts apoptosis in many cancer cell types (Verenich \& Gerk, 2010).

\subsection{Short chain alcohol dehydrogenase/reductase (SDR)}

Long-term exposure to estrogen and metabolites influences the development of breast cancer in women. The underlying mechanisms appear to be mainly involved in 1) estradiol/ER $\alpha$ signaling for stimulation of cell proliferation, and 2) formation of genotoxic metabolites of estradiol for binding to DNA and causing depurination and mutations (Santen et al., 2009). We suspect that naturally occurring dehydrogenases/reductases (including 17 $\beta$-HSDs), which possess binding sites for sex steroid hormones, may act as receptors and play an alternative role in breast cancer progression. For example, short-chain dehydrogenases/reductases (SDRs) are composed of a large family of $\operatorname{NAD}(\mathrm{P})(\mathrm{H})$ dependent oxidoreductases, sharing sequence motifs with similar functions (Kavanagh et al., 2008; Jörnvall et al., 2010). SDR enzymes play critical roles in metabolism for lipid, amino acid, carbohydrate, cofactor, and hormones, as well as in redox sensor mechanisms (Kavanagh et al., 2008). The SDR enzymes are normally 250-300 amino acid residues in length, which possesses a catalytic tetrad of Asn-Ser-Tyr-Lys (N-S-Y-K), and provides a platform for enzymatic activities encompassing several EC classes, including oxidoreductases, epimerases and lyases (Kavanagh et al., 2008).

\section{WW domain-containing Oxidoreductase}

\subsection{Tumor suppressor WWOX/FOR/WOX1 - a protein possessing WW and SDR domains}

WW domain-containing oxidoreductase, designated WWOX, FOR, or WOX1, is a protein possessing both WW domains and an SDR domain. The human and mouse WWOX/Wwox gene was first isolated independently by 3 laboratories in year 2000 (Smith et al., 2007; Del Mare et al., 2009; Chang et al., 2007, 2010; reviews). Human WWOX gene possesses approximately 1 million bases with 9 exons and codes for a 46-kDa protein containing 414 amino acids. Due to frequent genetic alterations, WWOX gene is generally considered as a tumor suppressor. The reason for the genetic alterations is probably associated with its localization on a common fragile site FRA16D on chromosome ch16q23.3-24.1. The WWOX gene encodes the WWOX/WOX1 protein. Substantial evidence reveals that this protein possesses a tumor suppressor function (Chang et al., 2007; Smith et al., 2007; Del 
Mare et al., 2009; Chang et al., 2010; Chang et al., 2001). It is documented that there is a relative high percentage of loss of heterozygosity (LOH) from 30 to $50 \%$ in human WWOX gene in many types of cancer cells (Chang et al., 2007; Smith et al., 2007; Del Mare et al., 2009; Chang et al., 2010).

The WWOX/WOX1 protein is composed of a nuclear localization sequence (NLS), two Nterminal WW domains (containing conserved tryptophan residues), a C-terminal short-chain alcohol dehydrogenase/reductase (SDR) domain, and probably a functional C-terminal tail named D3 (Hong et al., 2007; Hsu et al., 2008; Lin et al., 2011) (Figure 1). The putative tertiary structures of the first WW domain and the C-terminal SDR domain are shown. The solution structure of the second WW domain has been documented (Wang et al., 2007).

The $N$-terminal conserved first WW domain, which has been categorized as a group I WW domain, binds many proteins containing a PPXY motif(s), where $\mathrm{P}$ is proline, $\mathrm{Y}$ is tyrosine and $X$ is any amino acid (Chang et al., 2007; Smith et al., 2007; Del Mare et al., 2009; Chang et al., 2010). Among these WWOX/WOX1-binding protein targets are p73, activator protein $2 \gamma$ (AP-2, ErbB4, Ezrin, small integral membrane protein of the lysosome/late endosome (SIMPLE), c-Jun, and runt-related transcription factor 2 (RUNX2) (Chang et al., 2007; Del Mare et al., 2009; Chang et al., 2010). While most of the observations were from ectopic expression to enhance the binding, physiological consequences of the binding interactions are largely unknown.

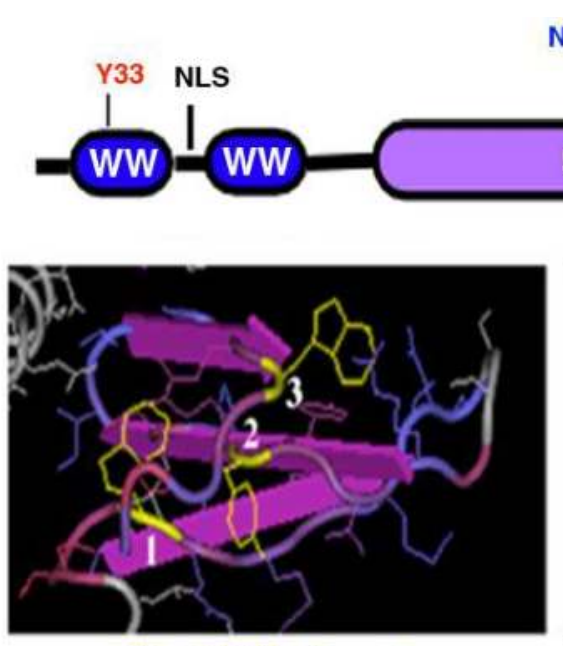

First WW domain

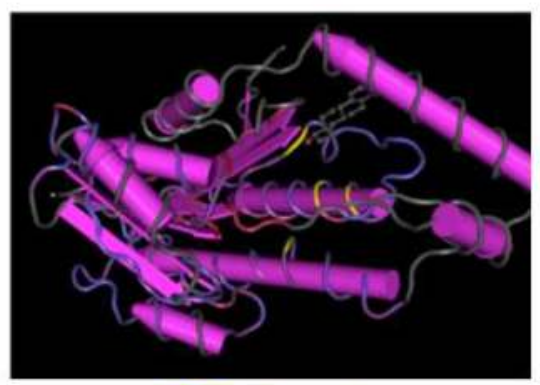

SDR domain

Fig. 1. WWOX and simulated tertiary structures. The predicted amino acid sequence of WW domain-containing oxidoreductase, designated WWOX, FOR, or WOX1, possesses two Nterminal WW domains, a nuclear localization signal sequence (NLS), and a C-terminal shortchain alcohol dehydrogenase/reductase (SDR) domain, where Tyr33 and Tyr287 are the hosphorylation sites, and NSYK is the binding motif for sex steroid hormones. Simulated structures of the first WW domain and the SDR domain are shown $(1=1$ st tryptophan; $2=$ Try33 phosphorylation site; $3=2^{\text {nd }}$ tryptophan; see yellow). Also, NSYK residues are marked in yellow. 
When WWOX/WOX1 becomes activated by stress stimuli such as UV light and tumor necrosis factor, Tyr33 is phosphorylated in the first WW domain (Chang, 2002; Chang et al., 2003a, 2003b, 2005a, 2007; Lai et al., 2005; Lo et al., 2008). Tyrosine kinase Src is known to phosphorylate Tyr33 in WWOX/WOX1 (Aqeilan et al., 2004a). The activated WWOX/WOX1 interacts with a large spectrum of proteins without possessing a PPXY motif(s), including proteins in the stress signaling and apoptotic response, as well as transcription factors (Chang et al., 2007, 2010; Del Mare et al., 2009). These proteins are p53 (Lo et al., 2008; Chang et al., 2001, 2003a, 2005a, 2005b; Lai et al., 2005), JNK1 (Lo et al., 2008; Chang et al., 2003a), MDM2 (Chang et al., 2005a), Zfra (Hong et al., 2007; Hsu et al., 2008), and Hyal-2 (Hsu et al., 2009).

The C-terminal SDR domain in WOX1/WWOX has been shown to bind Tau, a microtubulebinding protein involved in neurodegeneration (Sze et al., 2004). Functional consequence of this binding is also unknown. It is postulated that WOX1/WWOX binds Tau to prevent hyperphosphorylation by enzymes such as ERK, Cdk5, GSK-3 $\beta$ and JNK, thereby preventing tau aggregation as found in the hippocampi of patients with Alzheimer's disease (Sze et al., 2004). WOX1/WWOX physically interacts with MEK1 in T leukemia cells, and PMA (phorbol myristate acetate) modulates the binding interactions (Lin et al., 2011). PMAinduced dissociation of the WOX1/MEK1 interactions leads to apoptosis of Jurkat T cells, suggesting there is a critical switch in cell death for $\mathrm{T}$ cell leukemia upon the dissociation of WOX1/MEK1 (Lin et al., 2011). MEK1 has been shown to bind to both the WW and SDR domain of WOX1 with differential affinities. How this differential binding strength affects cell growth and death and correlates with biological activities is unknown and remains to be established.

\subsection{WWOX/WOX1 activation and its role in multiple signaling networks in vitro and in vivo}

WWOX/WOX1 interacts with many proteins in the stress signaling, growth, gene transcription, and apoptosis regulations, suggesting it is involved in multiple signal networks. For example, WWOX/WOX1 controls the activation of transcription factors, including p53 (Lo et al., 2008; Chang et al., 2001, 2003a, 2003b, 2005a, 2005b; Lai et al., 2005), p73 (Aqeilan et al., 2004a), AP2 $\gamma$ (Aqeilan et al., 2004b), c-Jun (Gaudio et al., 2006; Li et al., 2009), and CREB (Li et al., 2009). By immunoelectron microscopy, FRET (Förster resonance energy transfer) and co-immunoprecipitation, we have revealed the complex formation of the Tyr33-phosphorylated or activated WOX1 with p-CREB and p-c-Jun in vivo (Li et al., 2009). Interestingly, WOX1 blocks the prosurvival CREB-, CRE-, and AP-1-mediated promoter activation in vitro. In contrast, WOX1 enhances promoter activation regulated by c-Jun, Elk-1 and NF-кB (Li et al., 2009).

Tyr33-phosphorylated WOX1 is central to the stability and function of tumor suppressor p53. The activated WOX1 binds and stabilizes p53 with Ser46 phosphorylation, which is necessary for the apoptotic function of p53 (Chang et al., 2005a).

Numerous factors are known to induce Tyr33 phosphorylation in WWOX/WOX1, including sex steroid hormones (Chang et al., 2005b), transforming growth factor beta (Hsu et al., 2009), complement C1q (Hong et al., 2009), UV light, and anisomycin (Chang et al., 2001, 2003a, 2005a). Stress stimuli induce relocation of WWOX/WOX1 to the mitochondria and nuclei both in vitro and in vivo. When neurons are subjected to injury by axotomy, neurotoxin and long-term exposure to constant light in rats, WOX1 becomes activated via 
Tyr33 phosphorylation and accumulation in the mitochondria and nuclei (Chen et al., 2005; Lo et al., 2008; Li et al., 2009). Tyr287 in WWOX/WOX1 can undergo phosphorylation by activated tyrosine kinase 1 (Ack1) for polyubiquitination and protein degradation in prostate cancer cells (Mahajan et al., 2005).

\subsection{Alteration of human WWOX gene in cancer}

Cumulative reports have shown deletion or epigenetic alteration of human WWOX gene induces loss of protein expression in malignant cancer (Del Mare et al., 2009; Chang et al., 2007, 2010). For example, as demonstrated in most recent reports, both tumor suppressor genes FHIT and WWOX are deleted in primary effusion lymphoma (PEL) cell lines (Roy et al., 2011). Loss of WWOX occurs during the progression and development of gastric cancer (Maeda et al., 2010). Helicobacter pylori / H. pylori infection induces methylation of WWOX gene in human gastric cancer, suggestive of the role of epigenetic modification by $\mathrm{H}$. pylori in causing cancer (Yan et al., 2011). Interestingly, polymorphism Pro-282-Ala in WWOX gene may have a risk factor for differentiated thyroid carcinoma (Cancemi et al., 2011). Also, hypermethylation of $W W O X$ gene promoter region and mutations in the gene, encoding the SDR domain, appears to contribute to lung carcinogenesis (Baykara et al., 2010). Overall, it is not surprising to observe complete loss of WWOX gene and protein in invasive or metastatic cancer cells.

In most cases, cancer specimens from patients cannot represent the very early stages of cancer development. In this regard, our knowledge concerning how and when WWOX gene is altered is still lacking. We have examined the time-related Wwox gene alteration in hairless mice during the initiation and progression of cutaneous squamous cell carcinoma (SCC) (Lai et al., 2005). During the acute phase of UVB exposure in hairless mice, WOX1 protein was significantly upregulated and became activated in epidermal cells in 24 hours. After the inflammatory phase, the mice developed cutaneous SCC in 3 months, with significant reduction of WOX1 protein and its Tyr33 phosphorylation, but without downregulation of Wwox mRNA. In normal human and mouse skin, keratinocyte differentiation involves upregulation of human WWOX/WOX1, isoform WOX2, and Tyr33 phosphorylation prior to cornification and death (Lai et al., 2005). However, there are significant reductions in WOX1 and WOX2 proteins and their Tyr33 phosphorylation in non-metastatic and metastatic cutaneous SCC, but without down-regulation of WWOX mRNA. These observations suggest an additional mechanism for the inactivation of WWOX mRNA and a translational blockade of WWOX mRNA to protein.

By immunohistochemistry, it was reported that WWOX protein levels are not decreased but rather elevated in gastric and breast carcinoma (Watanabe et al., 2003), challenging the notion of WWOX as a classical tumor suppressor. Nonetheless, the stages of cancer cells are unknown. We have examined the hyperplasia stage of prostate cancer development and shown the increased expression levels of WWOX/WOX1 protein and isoforms (Chang et al., 2005b)

\subsection{WWOX/WOX1 localization and signaling}

Normal cells of the epithelial origin express WWOX/WOX1. These cells include skin keratinocytes and sebaceous gland cells, lung epithelial cells, epithelial cells of the digestive system, Leydig cells, follicular cells, prostate epithelial cells, and mammary gland cells. 
Many of these cells are responsive to stimulation by sex steroid hormones. During terminal differentiation of kerationcytes, WWOX/WOX1 expression is increased steadily prior to cornification. Whether this also reflects an increased oxidoreductase activity of WWOX/WOX1 in the keratinocytes is unknown. WWOX/WOX1 is accumulated in the nuclei during the terminal differentiation of keratinocytes (Lai et al., 2005). Substantial evidence shows that accumulation of WWOX/WOX1 in the nuclei may induce death of cancer cells in culture (Chang et al., 2007, 2010). Also, during axotomy, WWOX/WOX1, along with CREB, NF- $\mathrm{KB}$ and many transcription factors, relocates to the nuclei, and this appears to contribute to the eventual death of neurons ( $\mathrm{Li}$ et al., 2009). Similar observations for the accumulation of WWOX/WOX1 in the nuclei have been shown in animal models using neurotoxin MPP+ and long-term constant light exposure to cause neuronal death (Lo et al., 2008; Chen at al., 2005).

\subsubsection{WWOX/Ezrin interactions}

WWOX/WOX1 is known to be associated in part with the cell membrane/cytoskeleton area, and thereby serves as a sensor of environmental cues (Chang et al., 2010). WWOX/WOX1 receives and integrates signals from cell surface by undergoing Tyr33-phosphorylation and relocation to the nuclei in vitro and in vivo (Chang et al., 2010; review). Nuclear WWOX may either enhance or inhibit the promoter activities regulated by SMAD, NF- $\mathrm{kB}, \mathrm{c-JUN}, \mathrm{CREB}$ and other transcription factors (Gaudio et al., 2006; Li et al., 2009; Chang et al., 2010). By immunoelectron microscopy, WWOX/WOX1 can exist alone at the membrane/cytosleleton (Hsu et al., 2009), or it can be in binding with Ezrin (Jin el al., 2006), Hyal-2 (Hsu et al., 2009), or other cytoskeletal proteins (Cheng et al., unpublished). PKA-mediated phosphorylation of ezrin is central to the apical localization of WWOX protein in parietal cells, and that disruption of ezrin-WWOX interaction reduces the apical localization of WWOX (Jin et al., 2006). Ezrin directly binds to the first WW domain of WWOX via its C-terminal tyrosinecontaining polyproline sequence (470)PPPPPPVY(477) (Jin et al., 2006).

\subsubsection{TGF- $\beta / \mathrm{Hyal}-2 /$ WWOX/Smad4 signal pathway}

We have recently demonstrated that transforming growth factor beta (TGF- $\beta$ ) induces relocation of WWOX/WOX1 to the nuclei in response to TGF- $\beta 1$ in many types of cells, except in certain breast cancer cells (Hsu et al., 2009). Under physiological conditions, TGF$\beta 1$ binds membrane T $\beta R I I$ as a cognate receptor for recruiting T $\beta R I$, followed by phosphorylating Smad2 and 3, recruiting Smad4, and the Smad2/3/4 complex binding to responsive elements in the nucleus. In T $\beta$ RII-deficient HCT116 cells, we showed that membrane hyaluronidase Hyal-2 acts as a cognate receptor for TGF- $\beta 1$ (Hsu et al., 2009). TGF- $\beta 1$ binds to a surface-exposed segment in the catalytic domain of Hyal-2 in the microvilli, followed by rapidly recruiting WWOX. The WWOX/Hyal-2 complex appears to recruit Smad4 for enhancing SMAD-responsive promoter activation. Hyaluronan is also a ligand for Hyal-2, suggesting that both hyaluronan and TGF- $\beta 1$ may compete for the binding with membrane Hyal-2. Thus, we propose an alternative scenario that hyaluronan enhances the binding of TGF- $\beta 1$ with Hyal-2 without transmitting the signal. Presumably, TGF- $\beta 1$ is trapped on the cell surface by hyaluronan and Hyal-2. Upon hyaluronan degradation, the signal event may start. Two reports showed that hyaluronan blocks TGF- $\beta$ signaling by inducing trafficking of TGF- $\beta$ receptors to lipid raft-associated pools, which facilitates increased receptor turnover (Ito et al., 2004; Webber et al., 2009). 


\subsubsection{Complement protein C1q as an activator of WWOX/WOX1}

Purified serum C1q is able to rapidly induce the activation of WWOX/WOX1 (Hong et al., 2009). Complement C1q induces apoptosis of cancer cells overexpressing WWOX/WOX1, and the induced cell death is independent of the complement classical activation pathway. When WWOX/WOX1 is deficient in cells, C1q fails to cause apoptosis, indicating the presence of a novel pathway of programmed cell death. As determined by time-lapse surface plasmon-enhanced two-photon total internal reflection fluorescence (TIRF) microscopy (He et al., 2009, 2010), C1q induces the formation of clusters of microvilli and destabilizes the adherence in WOX1-overexpressing prostate DU145 cancer cells, without causing exposure of phosphatidylserine (PS) on the outer leaflet of the plasma membrane (Hong et al., 2009). Ultimately, these cells undergo shrinkage, membrane blebbing, and death (Hong et al., 2009). The observations suggest a critical role of WWOX/WOX1 in cell adherence and microvillus formation. Indeed, benign prostatic hyperplasia and prostate cancer have a significantly reduced expression of tissue C1q, compared to age-matched normal prostate tissues (Hong et al., 2009), suggesting that they can grow favorably as long as WWOX/WOX1 is also downregulated.

\subsection{A role of WWOX/WOX1 in metabolism}

\subsubsection{WWOX/WOX1 is associated with plasma HDL levels}

Low serum HDL-cholesterol (HDL-C) is known to be one of the risk factors for coronary artery disease. Three recent studies demonstrated that WWOX gene is associated with the alterations of plasma HDL levels (Lee et al., 2008; Sáez et al., 2010; Leduc et al., 2011). By genotyping of single nucleotide polymorphisms (SNPs), Lee et al. identified one SNP, rs2548861, in the intron 8 of WWOX gene with region-wide significance for low HDL-C in dyslipidemic families of Mexican and European descent and in low-HDL-C cases and controls of European descent. They concluded that there is a significant association between HDL-C and a WWOX variant with an allele-specific cis-regulatory function. Similar approaches, coupled with mouse genome mapping, were also used to indicate the association of WWOX gene with HDL cholesterol and triglyceride levels (Sáez et al., 2010; Leduc et al., 2011).

\subsubsection{WWOX/WOX1 plays a role in aerobic metabolism}

Genetic knockout models have revealed the functional properties of WWOX. In a Drosophila model, Wwox is shown to play a key role in aerobic metabolism probably via functional interactions with CG6439/isocitrate dehydrogenase (Idh) and Cu-Zn superoxide dismutase (Sod) (O'Keefe et al., 2011). Varied Wwox expression also causes altered levels of endogenous reactive oxygen species. A direct interaction between Wwox and the functional interactors has not been demonstrated.

\subsubsection{Wwox gene knockout mice models}

Targeted ablation of mouse Wwox gene at exons 2-4 appears to increase the incidence of spontaneous formation of tumors in heterozygous mice (Aqeilan et al., 2007). Importantly, the effect of Wwox gene knockout has a significant effect on bone metabolism defects (Aqeilan et al., 2008). The whole body Wwox gene-ablated mice can only survive for approximately one month. The molecular mechanism of this regard is not known. In 
addition, the knockout mice are also defective in the reproductive system (Ludes-Meyers et al., 2009). Inactivation of Wwox gene induces mammary tumorigenesis, and the tumors tend to have loss of estrogen receptor- $\alpha$ (ER) and progesterone receptor (Abdeen et al., 2011).

\section{WWOX/WOX1 is a candidate hormone receptor}

How breast cancer cells develop estrogen-independent growth is not known. Hormoneindependent breast cancer cells are normally ER-negative and highly invasive. Prognosis for patients is poor. WWOX/WOX1 possesses an NSYK motif for hormone binding. Depending upon cell lines, estrogen or androgen may induce WWOX/WOX1 phosphorylation at Tyr33 (Chang et al., 2005b). Activated WWOX/WOX1 relocates to the nucleus to induce apoptosis in certain cells. Conceivably, loss of WWOX/WOX1 in invasive breast cancer allows them to grow independently of hormones. TFAP2C plays a critical role in gene regulation in hormone responsive breast cancer. WWOX gene is one of the transcriptional targets of TFAP2C (Woodfield et al., 2010), suggesting a role of WWOX in the hormonal response.

\subsection{7 $\beta$-estradiol (E2) induces WWOX/WOX1 activation}

The NSYK motif for binding with estrogen and androgen in WWOX/WOX1 is predicted to be N232, S281, Y293, and K297 (Chang et al., 2003b; review). We have investigated whether androgen and estrogen activate WWOX/WOX1 (Chang et al., 2005b). In COS7 fibroblasts, E2 induces Tyr33 phosphorylation in WWOX/WOX1, and both E2 and WWOX/WOX1 cotranslocate to the nuclei (Chang et al., 2005b) (Figure 2). E2 at $\mu \mathrm{M}$ levels induces apoptosis of COS7 cells. It appears that when a sufficient amount of WWOX/WOX1 is accumulated in the nucleus, apoptosis occurs. However, it is not clear whether E2 binds to the NSYK motif. Indeed, E2 stimulates the formation of p53 and WOX1 complex, which is found in the nucleus (Chang et al., 2005b) (Figure 3). In contrast, JNK1 blocks the relocation of p53/WOX1 to the nucleus (Chang et al., 2005b). JNK1 binds and blocks WOX1 and p53 activation in vivo (Chang et al., 2003), and that dominant-negative JNK1 spontaneously induces WOX1 nuclear translocation. Whether there is a direct binding interaction between E2 and p53 or JNK1 is unknown.

E2 could not induce accumulation of WWOX/WOX1 in the nuclei of ER-positive breast MCF-7. ER-negative breast MDA-MB-231 and MDA-MB-435S are metastatic and have very low levels of WWOX/WOX1. Reconstitution of WWOX/WOX1 in these cells is expected to restore their sensitivity to estrogen. Interestingly, E2 and androsterone induce WWOX/WOX1 activation in androgen receptor (AR)-negative prostate DU145 cells, indicating that ER and AR are probably not involved in the E2-induced WWOX/WOX1 activation. Taken together, WWOX/WOX1 is a potential receptor for sex steroid hormones (Figure 4). Whether this protein metabolizes estrogen or androgen remains to be determined. Also, whether WWOX/WOX1 possesses an enzymatic activity in oxidation/reduction is still elusive.

\subsection{Estrogen-induced apoptosis}

Majority of ER-positive breast cancer cells depend upon estrogen for growth. It appears that these cells may become sensitive to estrogen-mediated apoptosis upon long-term deprivation of estrogen, followed by re-introducing estrogen. Whether WWOX/WOX1 is involved in the conferred sensitivity is not known. A recent study showed that AIB1 
(Amplified in Breast Cancer-1) is responsible for E2-mediated apoptosis in breast MCF-7: cells (Hu et al., 2011). Computational analysis revealed that AIB1 integrates signals from Gprotein-coupled receptors, PI3 kinase, Wnt and Notch signal pathways, which affect cell growth and death. Interestingly, it has been hypothesized that ER conformation affects E2induced cell death (Maximov et al., 2011).

\section{E2 induces WOX1 nuclear translocation}

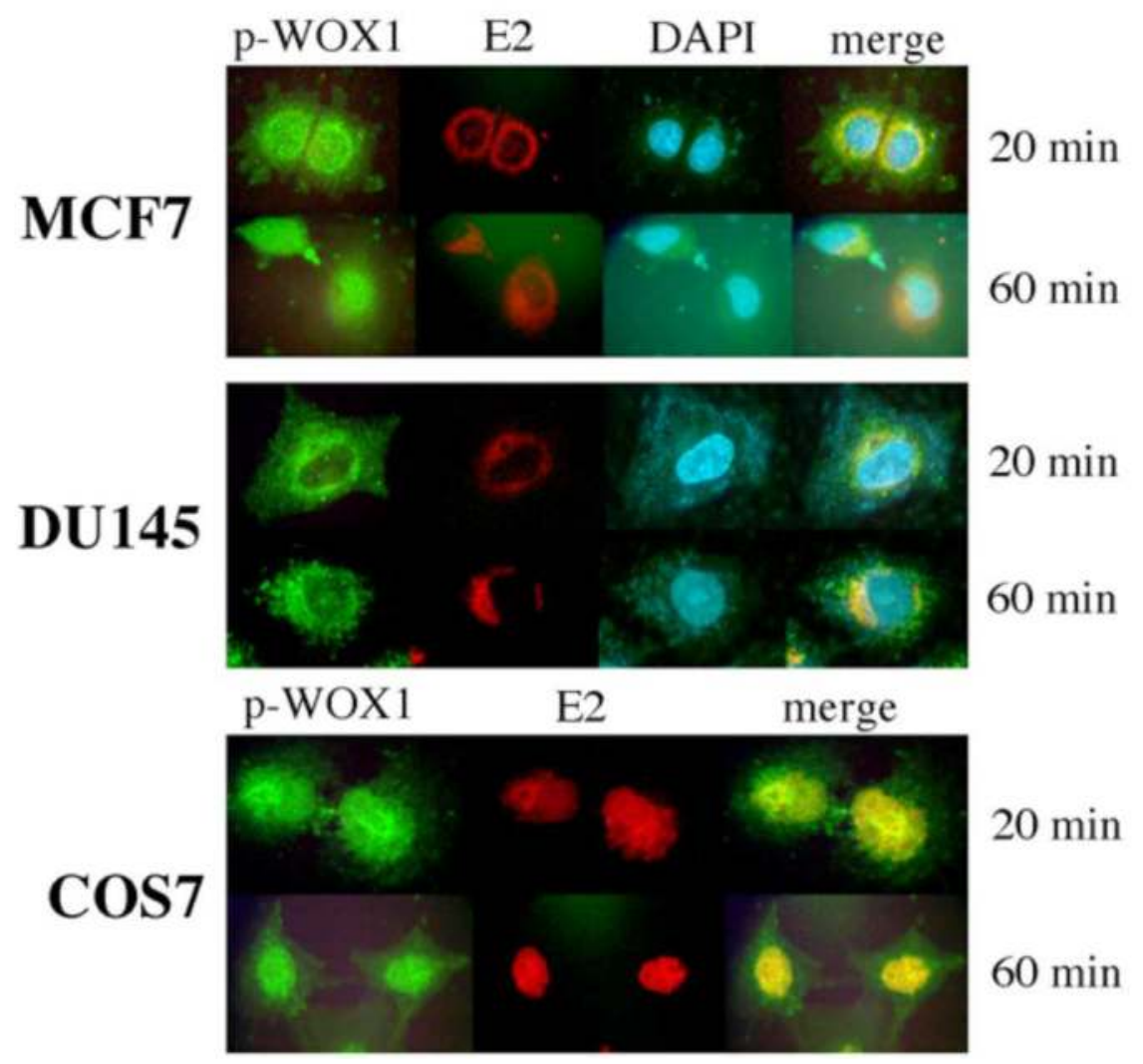

Fig. 2. 17ß-estradiol $\left(\mathrm{E}_{2}\right)$ stimulates phosphorylation of WWOX/WOX1 at Tyr33, and cotranalocation of WOX1 with E2 to the nucleus in COS7 fibroblasts. Stimulation of COS7 fibroblasts with E2 (40 nM) for $1 \mathrm{hr}$ resulted in activation of WOX1 via Tyr33 phosphorylation (p-WOX1) and nuclear translocation, along with E2. Both p-WOX1 and E2 were stained with specific antibodies. WOX1 undergoes activation in ER-positive MCF-7 cells, whereas E2 is retained in the cytoplasm. Both WOX1 and E2 are retained in the cytoplasm without undergoing nuclear translocation in AR-negative DU145 cells. 


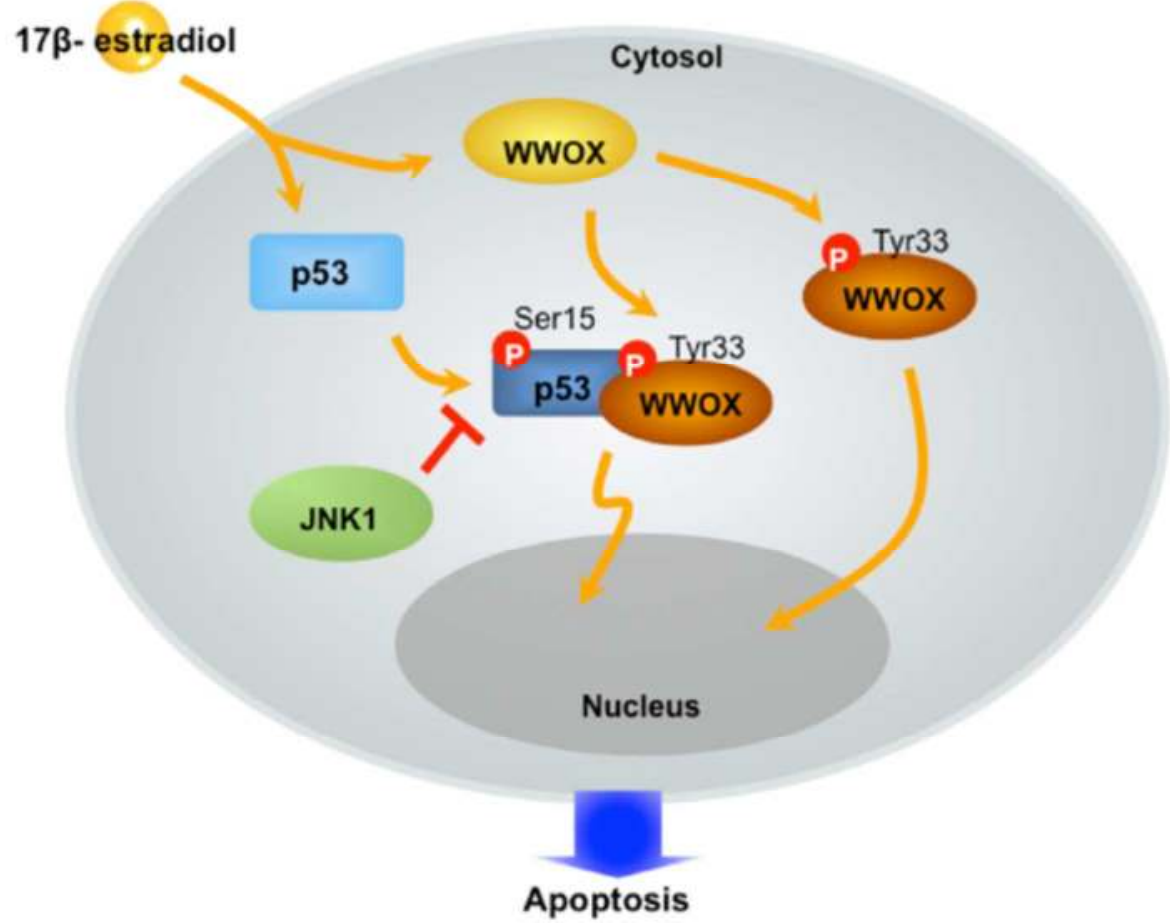

Fig. 3. E2 induces co-translocation of p53 and WWOX/WOX1 to the nuclei of COS7. In vitro experiments support the likely scenario that E2 induces the complex formation of Tyr33phosphorylated WOX1 and Ser15-phosphorylated p53, and the complex relocates to the nuclei (Chang et al., 2005b). JNK1 is also associated with the p53/WOX1 in the cytosol, but fails to undergo nuclear relocation. JNK1 blocks the nuclear accumulation of p53/WOX1.

\subsection{Hormone-independence in breast cancer and perspectives}

Development of hormone-independence in breast cancer patients involves a complicated event that underlies a network structure rather than individual molecular components. It is critical to probe the "disease systems" from a gene regulatory network to a cell, a tissue, or even an entire organism. Areas of this regard in terms of development independence in breast cancer are largely unknown. Invasive breast cancer cells exhibit a high frequency of loss of heterozygosity of WWOX gene. Wild type WWOX/WOX1 is responsive to estrogeninduced activation, via Tyr33 phosphorylation and nuclear translocation, for controlling cell growth. Thus, loss of WWOX gene in invasive breast cancer cells is likely to result in hormone resistance. 


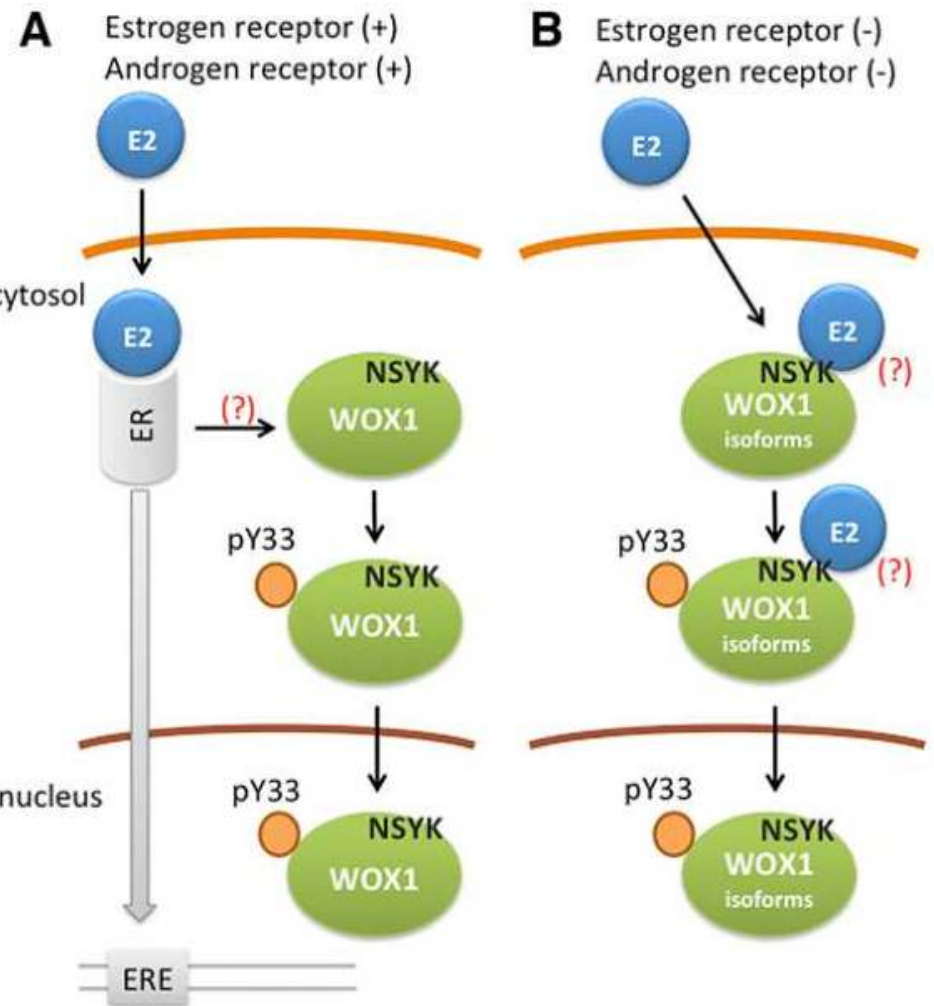

Fig. 4. Schematic illustration of E2/WWOX signaling. (A) In ER-positive cells, E2 binds ER and other proteins, and the complex translocates the nucleus to control gene transcription by binding to estrogen responsive elements (EREs) in chromosomal DNA. Alternatively, E2 may co-translocate with WOX1 to the nuclei. (B) In ER-negative, metastatic breast cancer cells, the wild type WWOX or WOX1 is deficient, whereas isoforms WOX2 and WOX8 may be present. These proteins provide the NSYK motif for binding with estrogen or androgen for relocating to the nucleus.

\section{Acknowledgement}

Research was supported, in part, by the Department of Defense, USA (W81XWH-08-1-0682), the National Science Council, Taiwan, ROC (NSC96-2320-B-006-014, 98-2628-B-006-041-MY3, and 98-2628-B-006-045-MY3), the National Health Research Institute, Taiwan, ROC (NHRIEX99-9705BI), and the National Cheng Kung University Landmark Projects (C0167 \& R026) (to NS Chang).

\section{References}

Abdeen S.K.; Salah Z.; Maly B.; Smith Y.; Tufail R.; Abu-Odeh M.; Zanesi N.; Croce C.M.; Nawaz Z. \& Aqeilan R.I. (2011). Wwox inactivation enhances mammary tumorigenesis. Oncogene, (Apr 2011), ISSN 
Aka J.A.; Mazumdar M. \& Lin S.X. (2009). Reductive 17beta-hydroxysteroid dehydrogenases in the sulfatase pathway: critical in the cell proliferation of breast cancer. Mol. Cell Endocrinol., Vol.301, No.1-2, (Mar 2009) pp. 183-190, Review, ISSN

Albin N.L.; Massaad C.; Toussaint M.C.; Mathieu J.; Morizet O.; Parise A.; Gouyette A. \& Chabot G.G. (1993). Main Drug-metabolizing Enzyme Systems in Human Breast Tumors and Peritumoral Tissues. Cancer Res, Vol.53, No.15, (Aug 1993) pp. 35413546, ISSN

Aqeilan R.I.; Hassan M.Q.; de Bruin A.; Hagan J.P.; Volinia S.; Palumbo T.; Hussain S.; Lee S.H.; Gaur T.; Stein G.S.; Lian J.B. \& Croce C.M (2008). The WWOX tumor suppressor is essential for postnatal survival and normal bone metabolism. J. Biol. Chem. Vol.283, No.31, (Aug 2008) pp. 21629-21639, ISSN

Aqeilan R.I.; Palamarchuk A.; Weigel R.J.; Herrero J.J.; Pekarsky Y. \& Croce C.M. (2004b) Physical and functional interactions between the Wwox tumor suppressor protein and the AP-2gamma transcription factor. Cancer Res, Vol.64, No.22, (Nov 2004) pp. 8256-61, ISSN

Aqeilan R.I.; Pekarsky Y.; Herrero J.J.; Palamarchuk A.; Letofsky J.; Druck T.; Trapasso F.; Han S.Y.; Melino G.; Huebner K. \& Croce C.M. (2004a). Functional association between Wwox tumor suppressor protein and p73, a p53 homolog. Proc. Natl. Acad. Sci. USA, Vol.101, No.13, (Mar 2004) pp. 4401-4406, ISSN

Aqeilan R.I.; Trapasso F.; Hussain S.; Costinean S.; Marshall D.; Pekarsky Y.; Hagan J.P.; Zanesi N.; Kaou M.; Stein G.S.; Lian J.B. \& Croce C.M. (2007). Targeted deletion of Wwox reveals a tumor suppressor function. Proc. Natl. Acad. Sci. USA, Vol.104, No.10, (Mar 2007) pp. 3949-3954, ISSN

Ball P. \& Knuppen R. (1980). Catecholoestrogens (2- and 4-hydroxyoestrogens): chemistry, biogenesis, metabolism, occurrence and physiological significance. Acta Endocrinol., Vol.232, (1980) pp. 1-127, ISSN

Baykara O., Demirkaya A., Kaynak K., Tanju S., Toker A., Buyru N. (2010) WWOX gene may contribute to progression of non-small-cell lung cancer (NSCLC). Tumour Biol Vol.31, No.4,(Aug 2010) pp.315-20, ISSN

Baykara O., Demirkaya A., Kaynak K., Tanju S., Toker A., Buyru N. (2010) WWOX gene may contribute to progression of non-small-cell lung cancer (NSCLC). Tumour Biol Vol.31, No.4,(Aug 2010) pp.315-20, ISSN

Blanchard P.G. \& Luu-The V. (2007). Differential androgen and estrogen substrates specificity in the mouse and primates type $1217 ß$-hydroxysteroid dehydrogenase. J. Endocrinol., Vol.194, No.2, (Aug 2007) pp. 449-455, ISSN

Cancemi L., Romei C., Bertocchi S., Tarrini G., Spitaleri I., Cipollini M., Landi D., Garritano S., Pellegrini G., Cristaudo A., Pinchera A., Barale R., Elisei R., Landi S., Gemignani F. (2011) Evidences that the polymorphism Pro-282-Ala within the tumor suppressor gene WWOX is a new risk factor for differentiated thyroid carcinoma. Int J Cancer Vol.129, No.12,(Dec 2011) pp.2816-24, ISSN

Cancemi L., Romei C., Bertocchi S., Tarrini G., Spitaleri I., Cipollini M., Landi D., Garritano S., Pellegrini G., Cristaudo A., Pinchera A., Barale R., Elisei R., Landi S., Gemignani F. (2011) Evidences that the polymorphism Pro-282-Ala within the tumor suppressor gene WWOX is a new risk factor for differentiated thyroid carcinoma. Int J Cancer Vol.129, No.12,(Dec 2011) pp.2816-24, ISSN 
Chang J.Y.; He R.Y.; Lin H.P.; Hsu L.J.; Lai F.J.; Hong Q.; Chen S.J. \& Chang N.S. (2010). Signaling from membrane receptors to tumor suppressor WW domain-containing oxidoreductase. Exp. Biol. Med. (Maywood), Vol.235, No.7, (Jul 2010) pp. 796-804, ISSN

Chang N.S. (2002). A potential role of p53 and WOX1 in mitochondrial apoptosis (review). Int. J. Mol. Med., Vol.9, No.1, (Jan 2002) pp. 19-24, ISSN

Chang N.S.; Doherty J. \& Ensign A. (2003a). JNK1 physically interacts with WW domaincontaining oxidoreductase (WOX1) and inhibits WOX1-mediated apoptosis. J. Biol. Chem. Vol. 278, No.11, (Mar 2003) pp. 9195-9202, ISSN

Chang N.S.; Doherty J.; Ensign A.; Lewis J.; Heath J.; Schultz L.; Chen S.T. \& Oppermann U. (2003b). Molecular mechanisms underlying WOX1 activation during apoptotic and stress responses. Biochem. Pharmacol., Vol.66, No.8, (Oct 2003) pp. 1347-1354, ISSN

Chang N.S.; Doherty J.; Ensign A.; Schultz L.; Hsu L.J. \& Hong Q. (2005a). WOX1 is essential for tumor necrosis factor-, UV light-, staurosporine-, and p53-mediated cell death, and its tyrosine 33-phosphorylated form binds and stabilizes serine 46phosphorylated p53. J. Biol. Chem., Vol.280, No.52, (Dec 2005) pp. 43100-43108, ISSN

Chang N.S.; Hsu L.J.; Lin Y.S.; Lai F.J. \& Sheu H.M. (2007). WW domain-containing oxidoreductase: a candidate tumor suppressor. Trends Mol. Med., Vol.13, No.1, (Jan 2007) pp. 12-22, ISSN

Chang N.S.; Pratt N.; Heath J.; Schultz L.; Sleve D.; Carey G.B. \& Zevotek N. (2001). Hyaluronidase induction of a WW domain-containing oxidoreductase that enhances tumor necrosis factor cytotoxicity. J. Biol. Chem., Vol.276, No.5, (Feb 2001) pp. 3361-3370, ISSN

Chang N.S.; Schultz L.; Hsu L.J.; Lewis J.; Su M. \& Sze C.I. (2005b). 17beta-Estradiol upregulates and activates WOX1/WWOXv1 and WOX2/WWOXv2 in vitro: potential role in cancerous progression of breast and prostate to a premetastatic state in vivo. Oncogene, Vol.24, No.4, (Jan 2005) pp. 714-723, ISSN

Chen J.Q.; Brown T.R. \& Yager J.D. (2008). Mechanisms of hormone carcinogenesis: evolution of views, role of mitochondria. Adv. Exp. Med. Biol., (2008) 630:1-18, Review, ISSN

Chen S.T.; Chuang J.I.; Cheng C.L.; Hsu L.J. \& Chang N.S. (2005). Light-induced retinal damage involves tyrosine 33 phosphorylation, mitochondrial and nuclear translocation of WW domain-containing oxidoreductase in vivo. Neuroscience, Vol.130, No.2, (2005) pp. 397-407, ISSN

Cheng Z.; Rios G.R.; King C.D.; Coffman B.L.; Green M.D.; Mojarrabi B.; Mackenzie P.I. \& Tephly T.R. (1998). Glucuronidation of catechol estrogens by expressed human UDP-glucuronosyltransferases (UGTs) 1A1, 1A3, and 2B7. Toxicol Sci., Vol.45, No1, (Sep 1998) pp. 52-57, ISSN

Del Mare S.; Salah Z. \& Aqeilan R.I. (2009). WWOX: its genomics, partners, and functions. J. Cell Biochem., Vol.108, No.4, (Nov 2009) pp. 737-745, ISSN

Desnoyers S.; Blanchard P.G.; St-Laurent J.F.; Gagnon S.N.; Baillie D.L. \& Luu-The V. (2007). Caenorhabditis elegans LET-767 is able to metabolize androgens and estrogens and likely shares common ancestor with human types 3 and 12 17beta-hydroxysteroid dehydrogenases. J. Endocrinol., Vol.195, No.2, (Nov 2007) pp.271-279, ISSN

Falany J.L. \& Falany C.N. (1996). Expression of Cytosolic Sulfotransferases in Normal Mammary Epithelial Cells and Breast Cancer Cell Lines1. Cancer Res, Vol.56, No.7, (Apr 1996) pp. 1551-1555, ISSN 
Filardo E.J.; Quinn J.A.; Frackelton A.R. Jr. \& Bland K.I. (2002). Estrogen action via the G protein-coupled receptor, GPR30: stimulation of adenylyl cyclase and cAMPmediated attenuation of the epidermal growth factor receptor-to-MAPK signaling axis. Mol. Endocrinol, Vol.16, No.1, (Jan 2002) pp. 70-84, ISSN

Fishman J. \& Martucci C. (1980). Biological properties of 16alpha-hydroxyestrone: Implications in estrogen physiology and pathophysiology. J. Clin. Endocrinol Metab., Vol.51, No.3, (Sep 1980) pp. 611-615, ISSN

Gaudio E.; Palamarchuk A.; Palumbo T.; Trapasso F.; Pekarsky Y.; Croce C.M. \& Aqeilan R.I. (2006). Physical association with WWOX suppresses c-Jun transcriptional activity. Cancer Res, Vol.66, No.24, (Dec 2006) pp. 11585-11589, ISSN

Geissler W.M.; Davis D.L.; Wu L.; Bradshaw K.D.; Patel S.; Mendonca B.B.; Elliston K.O.; Wilson J.D.; Russell D.W. \& Andersson S. (1994). Male pseudohermaphroditism caused by mutations of testicular 17 beta-hydroxysteroid dehydrogenase 3. Nat. Genet., Vol.7, No.1, (May 1994) pp. 34-39, ISSN

Hartman J.; Edvardsson K.; Lindberg K.; Zhao C.; Williams C.; Strom A. \& Gustafsson J.A. (2009). Tumor repressive functions of estrogen receptor B in SW480 colon cancer cells. Cancer Res, Vol.69, No.15, (Aug 2009) pp. 6100-6106, ISSN

He R.Y.; Lin C.Y.; Su Y.D.; Chiu K.C.; Chang N.S.; Wu H.L. \& Chen S.J. (2010). Imaging live cell membranes via surface plasmon-enhanced fluorescence and phase microscopy. Opt. Express, Vol.18, No.4, (Feb 2010) pp. 3649-3659, ISSN

He R.Y.; Su Y.D.; Cho K.C.; Lin C.Y.; Chang N.S.; Chang C.H. \& Chen S.J. (2009). Surface plasmon-enhanced two-photon fluorescence microscopy for live cell membrane imaging. Opt. Express, Vol.17, No.8, (Apr 2009) pp. 5987-5997, ISSN

Hernandez, J.S.; Watson R.W.; Wood TC \& Weinshilboum R.M. (1992). Sulfation of estrone and $17 \beta$-estradiol in human liver. Catalysis by thermostable phenol sulfotransferase and by dehydroepiandrosterone sulfotransferase. Drug Metab. Dispos., Vol.20, No.3, (May-Jun 1992) pp. 413-422, ISSN

Hong Q.; Hsu L.J.; Schultz L.; Pratt N.; Mattison J. \& Chang N.S. (2007). Zfra affects TNFmediated cell death by interacting with death domain protein TRADD and negatively regulates the activation of NF-kappaB, JNK1, p53 and WOX1 during stress response. BMC Mol. Biol., Vol.8, (Jun 2007) pp. 50, ISSN

Hong Q.; Sze C.I.; Lin S.R.; Lee M.H.; He R.Y.; Schultz L.; Chang J.Y.; Chen S.J.; Boackle R.J.; Hsu L.J. \& Chang N.S. (2009). Complement C1q activates tumor suppressor WWOX to induce apoptosis in prostate cancer cells. PLoS One, Vol.4, No.6, (Jun 2009) p. e5755, ISSN

Hsu L.J.; Hong Q.; Schultz L.; Kuo E.; Lin S.R.; Lee M.H.; Lin Y.S. \& Chang N.S. (2008). Zfra is an inhibitor of Bcl-2 expression and cytochrome c release from the mitochondria. Cell Signal, Vol.20, No.7, (Jul 2008) pp. 1303-1312, ISSN

Hsu L.J.; Schultz L.; Hong Q.; Van Moer K.; Heath J.; Li M.Y.; Lai F.J.; Lin S.R.; Lee M.H.; Lo C.P.; Lin Y.S.; Chen S.T. \&Chang N.S. (2009). Transforming growth factor beta1 signaling via interaction with cell surface Hyal-2 and recruitment of WWOX/WOX1. J. Biol. Chem., Vol.284, No.23, (Jun 2009) pp. 16049-16059, ISSN

$\mathrm{Hu}$ ZZ, Kagan BL, Ariazi EA, Rosenthal DS, Zhang L, Li JV, Huang H, Wu C, Jordan VC, Riegel AT, Wellstein A. (2011) Proteomic analysis of pathways involved in estrogen-induced growth and apoptosis of breast cancer cells. PLoS One Vol. 6. No. 6,(July 27) p.e20410, ISSN 
Huang H.J.; Chiang P.H. \& Chen S.H. (2011). Quantitative analysis of estrogens and estrogen metabolites in endogenous MCF-7 breast cancer cells by liquid chromatography-tandem mass spectrometry. J. Chromatogr. B., Vol.879, No.20, (Jun 2011) pp. 1748-1756, ISSN

Ito T.; Williams JD.; Fraser DJ. \& Phillips AO. (2004). Hyaluronan regulates transforming growth factor-beta1 receptor compartmentalization. J Biol Chem, Vol.279, No. 24, (Jun 2004) pp.25326-25332, ISSN

Jansson A. (2009). 17Beta-hydroxysteroid dehydrogenase enzymes and breast cancer. J. Steroid Biochem. Mol. Biol., Vol.114, No.1-2, (Mar 2009) pp. 64-67, Review, ISSN

Jansson A.; Delander L.; Gunnarsson C.; Fornander T.; Skoog L.; Nordenskjöld B. \& Stål O. (2009). Ratio of 17HSD1 to 17HSD2 protein expression predicts the outcome of tamoxifen treatment in postmenopausal breast cancer patients. Clin. Cancer Res, Vol.15, No.10, (May 2009) pp. 3610-3616, ISSN

Jin C.; Ge L.; Ding X.; Chen Y.; Zhu H.; Ward T.; Wu F.; Cao X.; Wang Q. \& Yao X. (2006). PKA-mediated protein phosphorylation regulates ezrin-WWOX interaction. Biochem. Biophys. Res Commun., Vol.341, No.3, (Mar 2006) pp. 784-791, ISSN

Jörnvall H.; Hedlund J.; Bergman T.; Oppermann U. \& Persson B. (2010). Superfamilies SDR and MDR: from early ancestry to present forms. Emergence of three lines, a Znmetalloenzyme, and distinct variabilities. Biochem. Biophys. Res Commun., Vol.396, No.1, (May 2010) pp. 125-130, Review, ISSN

Joubert A.; Van Zyl H.; Laurens J. \& Lottering M.L. (2009). C2- and C4-position 17betaestradiol metabolites and their relation to breast cancer. Biocell, Vol.33, No.3, (Dec 2009) pp. 137-140, Review, ISSN

Kavanagh K.L.; Jörnvall H.; Persson B. \& Oppermann U. (2008). Medium- and short-chain dehydrogenase/reductase gene and protein families : the SDR superfamily: functional and structural diversity within a family of metabolic and regulatory enzymes. Cell Mol. Life Sci., Vol.65, No.24, (Dec 2008) pp. 3895-3906, Review, ISSN

Lai F.J.; Cheng C.L.; Chen S.T.; Wu C.H.; Hsu L.J.; Lee J.Y.; Chao S.C.; Sheen M.C.; Shen C.L.; Chang N.S. \& Sheu H.M. (2005). WOX1 is essential for UVB irradiation-induced apoptosis and down-regulated via translational blockade in UVB-induced cutaneous squamous cell carcinoma in vivo. Clin. Cancer Res, Vol.11, No.16, (Aug 2005) pp. 5769-5777, ISSN

Leduc M.S.; Lyons M.; Darvishi K.; Walsh K.; Sheehan S.; Amend S.; Cox A.; Orho-Melander M.; Kathiresan S.; Paigen B. \& Korstanje R. (2011). The mouse QTL map helps interpret human genome-wide association studies for HDL cholesterol. J. Lipid Res, Vol.52, No.6, (Jun 2011) pp. 1139-1149, ISSN

Lee J.C.; Weissglas-Volkov D.; Kyttälä M.; Dastani Z.; Cantor R.M.; Sobel E.M.; Plaisier C.L.; Engert J.C.; van Greevenbroek M.M.; Kane J.P.; Malloy M.J.; Pullinger C.R.; HuertasVazquez A.; Aguilar-Salinas C.A.; Tusie-Luna T.; de Bruin T.W.; Aouizerat B.E.; van der Kallen C.C.; Croce C.M.; Aqeilan R.I.; Marcil M.; Viikari J.S.; Lehtimäki T.; Raitakari O.T.; Kuusisto J.; Laakso M.; Taskinen M.R.; Genest J. \& Pajukanta P. (2008). WW-domain-containing oxidoreductase is associated with low plasma HDL-C levels. Am. J. Hum. Genet, Vol.83, No.2, (Aug 2008) pp. 180-192, ISSN

Li M.Y.; Lai F.J.; Hsu L.J.; Lo C.P.; Cheng C.L.; Lin S.R.; Lee M.H.; Chang J.Y.; Subhan D.; Tsai M.S.; Sze C.I.; Pugazhenthi S.; Chang N.S. \& Chen S.T. (2009). Dramatic coactivation of WWOX/WOX1 with CREB and NF-kappaB in delayed loss of small 
dorsal root ganglion neurons upon sciatic nerve transection in rats. PLoS One, Vol.4, No.11, (Nov 2009) pp. e7820, ISSN

Lin H.P.; Chang J.Y.; LinS.R.; Lee M.H.; Huang S.S.; Hsu L.J. \& Chang N.S. (2011). Identification of an in vivo MEK/WOX1 complex as a master switch for apoptosis in T cell leukemia. Genes $\mathcal{E}$ Cancer, in press.

Liu H.; Zheng S.; Bellemare V.; Pelletier G.; Labrie F. \& Luu-The V. (2007). Expression and localization of estrogenic type 12 17beta-hydroxysteroid dehydrogenase in the cynomolgus monkey. B.M.C. Biochem., Vol8, (Feb 2007) pp. 2, ISSN

Lo C.P.; Hsu L.J.; Li M.Y.; Hsu S.Y.; Chuang J.I.; Tsai M.S.; Lin S.R.; Chang N.S. \& Chen S.T. (2008). MPP+-induced neuronal death in rats involves tyrosine 33 phosphorylation of WW domain-containing oxidoreductase WOX1. Eur J Neurosci., Vol.27, No.7, (Apr 2008) pp. 1634-1646, ISSN

Ludes-Meyers J.H.; Kil H.; Parker-Thornburg J.; Kusewitt D.F.; Bedford M.T. \& Aldaz C.M. (2009). Generation and characterization of mice carrying a conditional allele of the Wwox tumor suppressor gene. PLoS One, Vol.4, No.11, (Nov 2009) p. e7775, ISSN

Maeda N.; Semba S.; Nakayama S.; Yanagihara K. \& Yokozaki H. (2010). Loss of WW domain-containing oxidoreductase expression in the progression and development of gastric carcinoma: clinical and histopathologic correlations. Virchows Arch, Vol.457, No.4, (Oct 2010) pp. 423-32, ISSN

Mahajan N.P.; Whang Y.E.; Mohler J.L. \& Earp H.S. (2005). Activated tyrosine kinase Ack1 promotes prostate tumorigenesis: role of Ack1 in polyubiquitination of tumor suppressor Wwox. Cancer Res, Vol.65, No.22, (Nov 2005) pp. 10514-10523, ISSN

Marchais-Oberwinkler S.; Henn C.; Möller G.; Klein T.; Negri M.; Oster A.; Spadaro A.; Werth R.; Wetzel M.; Xu K.; Frotscher M.; Hartmann R.W. \& Adamski J. (2011). $17 \beta$-Hydroxysteroid dehydrogenases (17 $\beta$-HSDs) as therapeutic targets: Protein structures, functions, and recent progress in inhibitor development. J. Steroid Biochem. Mol. Biol., Vol.125, No.1-2, (May 2011) pp. 66-82, ISSN

Markides C.S. \& Liehr J.G. (2005). Specific binding of 4-hydroxyestradiol to mouse uterine protein: evidence of a physiological role for 4-hydroxyestradiol. J. Endocrinol, Vol.185, No.2, (May 2005) pp. 235-242, ISSN

Martucci, C.P. \& Fishman, J. (1993). P450 enzymes of estrogen metabolism. Pharmacol. Ther., Vol.57, No.2-3, (Feb-Mar 1993) pp. 237-257, Review, ISSN

Maximov P., Sengupta S., Lewis-Wambi J.S., Kim H.R., Curpan R.F., Jordan V.C. (2011) The Conformation of the Estrogen Receptor Directs Estrogen-Induced Apoptosis in Breast Cancer: A Hypothesis. Horm Mol Biol Clin Investig Vol.5, No.1,(Mar 2011) pp.27-34, ISSN

McDonnel D.P. \& Norris J.D. (2002). Connections and regulation of the human estrogen receptor. Science, Vol.296, No.5573, (May 2002) pp. 1642-1644, ISSN

Miki Y.; Suzuki T. \& Sasano H. (2009). Intracrinology of sex steroids in ductal carcinoma in situ (DCIS) of human breast: comparison to invasive ductal carcinoma (IDC) and non-neoplastic breast. J. Steroid Biochem. Mol. Biol., Vol.114, No.1-2, (Mar 2009) pp. 68-71, Review, ISSN

Miro A.M.; Sastre-Serra J.; Ponsa D.G.; Vallea A.; Rocaa P. \& Oliver J. (2011). 17 $\beta$-Estradiol regulates oxidative stress in prostate cancer cell lines according to ERalpha/ERbeta ratio. Journal of Steroid Biochemistry \& Molecular Biology, Vol.123, No.3-5, (Feb 2011) pp. 133-139, ISSN 
Mosselman S.; Polman J. \& Dijkema R. (1996). ER beta: identification and characterization of a novel human estrogen receptor. FEBS Lett., Vol.392, No.1, (Aug 1996) pp. 49-53, ISSN

Mueck A.O. \& Seeger H. (2007). Breast cancer: are estrogen metabolites carcinogenic? Climacteric., Suppl. 2, (Oct 2007) pp. 62-65, Review, ISSN

Nilsen J. (2008). Estradiol and neurodegenerative oxidative stress. (2008). Front Neuroendocrinol., Vol.29, No.4, (Oct 2008) pp. 463-475, Review, ISSN

Obi N.; Vrieling A.; Heinz J. \& Chang-Claude J. (2011). Estrogen metabolite ratio: Is the 2hydroxyestrone to 16a-hydroxyestrone ratio predictive for breast cancer? Int. J. Womens Health, Vol.3, (Feb 2011) pp. 37-51, ISSN

O'Keefe L.V.; Colella A.; Dayan S.; Chen Q.; Choo A.; Jacob R.; Price G.; Venter D. \& Richards R.I. (2011). Drosophila orthologue of WWOX, the chromosomal fragile site FRA16D tumour suppressor gene, functions in aerobic metabolism and regulates reactive oxygen species. Hum.Mol.Genet, Vol.20, No.3, (Feb 2011) pp. 497-509, ISSN

Okoh V.; Deoraj A. \& Roy D. (2011). Estrogen-induced reactive oxygen species-mediated signalings contribute to breast cancer. Biochim. Biophys. Acta., Vol.1815, No.1, (Jan 2011) pp. 115-133, Review, ISSN

Roy D.; Sin S.H.; Damania B. \& Dittmer D.P. (2011). Tumor suppressor genes FHIT and WWOX are deleted in primary effusion lymphoma (PEL) cell lines. Blood, (Jun 2011), ISSN

Sáez M.E.; González-Pérez A.; Martínez-Larrad M.T.; Gayán J.; Real L.M.; Serrano-Ríos M. \& Ruiz A. (2010). WWOX gene is associated with HDL cholesterol and triglyceride levels. B.M.C. Med. Genet, Vol.11, (Oct 2010) pp.148, ISSN

Santen R.; Cavalieri E.; Rogan E.; Russo J.; Guttenplan J.; Ingle J. \& Yue W. (2009). Estrogen mediation of breast tumor formation involves estrogen receptor-dependent, as well as independent, genotoxic effects. Ann. N. Y. Acad. Sci., Vol.1155, (Feb 2009) pp. 132-140, Review, ISSN

Sasaki Y.; Miki Y.; Hirakawa H.; Onodera Y.; Takagi K.; Akahira J.; Honma S.; Ishida T.; Watanabe M.; Sasano H. \& Suzuki T. (2010). Immunolocalization of estrogenproducing and metabolizing enzymes in benign breast disease: comparison with normal breast and breast carcinoma. Cancer Sci., Vol.101, No.10, (Oct 2010) pp. 2286-2292, ISSN

Sepkovic D.W. \& Bradlow H.L. (2009). Estrogen hydroxylation--the good and the bad. Ann. N. Y. Acad. Sci., Vol.1155, (Feb 2009) pp.57-67, Review, ISSN

Smith D.I.; McAvoy S.; Zhu Y. \& Perez D.S. (2007). Large common fragile site genes and cancer. Semin Cancer Biol., Vol.17, No.1, (Feb 2007) pp. 31-41, ISSN

Straub R.H. (2007). The complex role of estrogens in inflammation. Endocr. Rev., Vol.28, No.5, (Aug 2007) pp. 521-574, Review, ISSN

Swaneck G.E. \& Fishman J. (1988). Covalent binding of the endogenous estrogen 16 alphahydroxyestrone to estradiol receptor in human breast cancer cells: Characterization and intranuclear localization. Proc. Natl. Acad. Sci. USA, Vol.85, No21, (Nov 1988) pp. 7831-7835, ISSN

Sze C.I.; Su M.; Pugazhenthi S.; Jambal P.; Hsu L.J.; Heath J.; Schultz L. \& Chang N.S. (2004). Down-regulation of WW domain-containing oxidoreductase induces Tau phosphorylation in vitro. A potential role in Alzheimer's disease. J. Biol. Chem., Vol.279, No.29, (Jul 2004) pp. 30498-30506, ISSN 
Tam A.; Morrish D.; Wadsworth S.; Dorscheid D.; Man S.P. \& Sin D.D. (2011). The role of female hormones on lung function in chronic lung diseases. B.M.C. Womens Health, Vol.11, (Jun 2011) pp. 24, ISSN

Verenich S. \& Gerk P.M. (2010). Therapeutic promises of 2-methoxyestradiol and its drug disposition challenges. Mol. Pharm., Vol.7, No.6, (Dec 2010) pp. 2030-2039, Review, ISSN

Wang Y.; Addess K.J.; Chen J.; Geer L.Y.; He J.; He S.; Lu S.; Madej T.; Marchler-Bauer A.; Thiessen P.A.; Zhang N. \& Bryant S.H. (2007). MMDB: annotating protein sequences with Entrez's 3D-structure database. Nucleic Acids Res, (Jan 2007) 35(Database issue):D298-300, ISSN

Watanabe A., Hippo Y., Taniguchi H., Iwanari H., Yashiro M., Hirakawa K., Kodama T., Aburatani H. (2003) An opposing view on WWOX protein function as a tumor suppressor. Cancer Res Vol.63, No.24,(Dec 2003) pp.8629-33, ISSN

Watanabe A., Hippo Y., Taniguchi H., Iwanari H., Yashiro M., Hirakawa K., Kodama T., Aburatani H. (2003) An opposing view on WWOX protein function as a tumor suppressor. Cancer Res Vol.63, No.24,(Dec 2003) pp.8629-33, ISSN

Webber J.; Jenkins RH.; Meran S.; Phillips A. \& Steadman R. (2009). Modulation of TGFbeta1-dependent myofibroblast differentiation by hyaluronan. Am J Pathol, Vol.175, No.1, (Jul 2009) pp. 148-160, ISSN

Woodfield G.W.; Chen Y.; Bair T.B.; Domann F.E.; Weigel R.J. (2010). Identification of primary gene targets of TFAP2C in hormone responsive breast carcinoma cells. Genes Chromosomes Cancer, Vol.49, No.10, (Oct 2010) pp. 948-962, ISSN

Wu C.J.; Chen Y.W.; Tai J.H. \& Chen S.H. (2011). Quantitative phosphoproteomics studies using stable isotope dimethyl labeling coupled with IMAC-HILIC-nanoLC-MS/MS for estrogen-induced transcriptional regulation. J. Proteome Res, Vol.10, No.3, (Mar 2011) pp. 1088-1097, ISSN

Yan J., Zhang M., Zhang J., Chen X., Zhang X. (2011) Helicobacter pylori infection promotes methylation of WWOX gene in human gastric cancer. Biochem Biophys Res Commun Vol.408, No.1,(Apr 2011) pp.99-102, ISSN

Yan J., Zhang M., Zhang J., Chen X., Zhang X. (2011) Helicobacter pylori infection promotes methylation of WWOX gene in human gastric cancer. Biochem Biophys Res Commun Vol.408, No.1,(Apr 2011) pp.99-102, ISSN

Yeh M.C.S.; Ni J.; Yin Y.; Chang E.; Zang M. \& Wen X. (2005). Functions of estrogen receptor in prostate and prostate cancer, in: Basic Mechanisms and Therapeutic Approaches. W.S. Publishing, New Jersey, 2005, pp. 293-313

Zhu B.T. \& Conney A.H. (1998). Functional role of estrogen metabolism in target cells: review and perspectives. Carcinogenesis, Vol.19, No.1, (Jan 1998) pp. 1-27, ISSN

Zhu, B.T.; Suchar, L.S.; Huang, M.-T. \& Conney, A.H. (1996). Similarities and differences in the glucuronidation of estradiol and estrone by UDPglucuronosyltransferase in liver microsomes from male and female rats. Biochem. Pharmacol., Vol.51, No.9, (May 1996) pp. 1195-1202, ISSN 


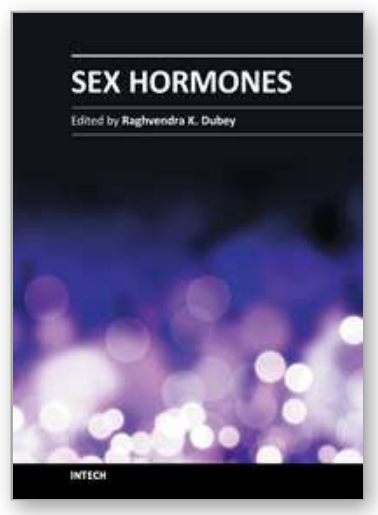

\author{
Sex Hormones \\ Edited by Prof. Raghvendra Dubey
}

ISBN 978-953-307-856-4

Hard cover, 430 pages

Publisher InTech

Published online 08, February, 2012

Published in print edition February, 2012

Sex Hormones not only regulate reproductive function, but they also play a prominent role in the biology and physiology of several organs/tissues and in the pathophysiology of several diseases. During the last two decades, the information on the mechanisms of action of sex hormones, such as estrogens and androgens, has rapidly evolved from the conventional nuclear receptor dependent mechanisms to include additional nonnuclear, non-genomic and receptor-independent mechanisms. This highlights the need to update the current knowledge on sex hormones and their mode of action. Increasing evidence that exogenous/epigenetic factors can influence sex hormone production and action highlights the need to update our knowledge on the mechanisms involved. This book provides a systematic and updated overview of the male/female sexhormones and their impact in the biology and physiology of various organs. Additionally, the book discusses their positive and negative association with the pathophysiology of various diseases (e.g. osteoporosis, cardiovascular-disease, hypogonadism, reproduction, cancer) and their therapeutic potential.

\title{
How to reference
}

In order to correctly reference this scholarly work, feel free to copy and paste the following:

Won-Pei Su, Shu-Hui Chen, Szu-Jung Chen, Pei-Yi Chou, Chun-Cheng Huang and Nan-Shan Chang (2012). WW Domain-Containing Oxidoreductase is a Potential Receptor for Sex Steroid Hormones, Sex Hormones, Prof. Raghvendra Dubey (Ed.), ISBN: 978-953-307-856-4, InTech, Available from:

http://www.intechopen.com/books/sex-hormones/ww-domain-containing-oxidoreductase-is-a-potentialreceptor-for-sex-steroid-hormones

\section{INTECH}

open science | open minds

\section{InTech Europe}

University Campus STeP Ri

Slavka Krautzeka 83/A

51000 Rijeka, Croatia

Phone: +385 (51) 770447

Fax: +385 (51) 686166

www.intechopen.com

\section{InTech China}

Unit 405, Office Block, Hotel Equatorial Shanghai

No.65, Yan An Road (West), Shanghai, 200040, China 中国上海市延安西路65号上海国际贵都大饭店办公楼 405 单元

Phone: +86-21-62489820

Fax: $+86-21-62489821$ 
(C) 2012 The Author(s). Licensee IntechOpen. This is an open access article distributed under the terms of the Creative Commons Attribution 3.0 License, which permits unrestricted use, distribution, and reproduction in any medium, provided the original work is properly cited. 